\title{
OUTCOME OF ORAL PROGESTERONE THERAPY IN PREVENTION OF PRETERM LABOR.
}

\author{
DR. KHIZRA MUSSADIQ, MBBS \\ NISHTAR HOSPITAL, MULTAN, PAKISTAN. \\ DR. HIRA AWAN, MBBS \\ WMO, DISTRICT HEADQUARTERS HOSPITAL, KHANEWAL, PAKISTAN. \\ DR. MAHNOOR WAHID, MBBS \\ NISHTAR HOSPITAL, MULTAN, PAKISTAN.
}

\begin{abstract}
;
Objectives; To determine the outcome of oral progesterone therapy in prevention of preterm labor at a tertiary care hospital. Material and methods; All women (345) with previous history of preterm delivery, aged less than 45 years of age having their gestational ages 15 - 20 weeks were included from January 2018 to May 2019 at Department of Gynecology and Obstetrics, Nishtar Hospital Multan. These study cases were given $400 \mathrm{mg}$ oral progesterone every day till delivery and were followed till delivery to record prevention of preterm birth (efficacy; birth of a baby with more than 37 weeks gestational age assessed on LMP treated with oral progesterone). Data were analyzed by using SPSS Version 20. Results; Mean age of our study cases was $30.12 \pm$ 4. 83 years. Mean parity of our study cases was $4.52 \pm 1.19$. Mean gravidity of our study cases was $5.66 \pm 1.18$. Mean gestational age of our study cases was $37.51 \pm 1.34$ weeks at the time of delivery. Mean body mass index of our study cases was $23.39 \pm 2.87 \mathrm{~kg} / \mathrm{m}^{2}$. Our study results have indicated that obesity was present in 83 (24.1\%) study cases. Of these 345 study cases, $180(52.2 \%)$ belonged to urban areas, $328(95.1 \%)$ had singleton pregnancy and previous no. of preterm births ranging from $1-2$ was noted in $240(69.57 \%)$. Treatment with oral progesterone prevented preterm labor in $231(67 \%)$ of the study cases. Conclusion; Our study results support the use of oral progesterone as use of oral progesterone was successful in preventing preterm labor in our study. Its use was found to be safe and reliable, hence can be given to the women with previous history of preterm birth without any adverse side effect. The prevention of preterm birth was significantly associated with age, parity, gravidity, no. of previous preterm births, order of pregnancy and residential status.
\end{abstract}

Keywords; Oral Progesterone, Prevention, Preterm birth.

DOI: $10.7176 / \mathrm{JMPB} / 55-08$

Publication date:May $31^{\text {st }} 2019$

\section{Introduction;}

Preterm births are most commonly reported issue in mother-child health all over the world ${ }^{1}$. Preterm births complicate 1 in eight births among developed nations and is responsible for approximately $90 \%$ perinatal morbidities and mortalities ${ }^{2,3}$. Efforts regarding prevention of preterm births have largely been failed, even though there is tremendous level of obstetrician efforts involved to specify such patients at risk of preterm births were up to the mark in terms of measurement of transvaginal cervical length and cervicovaginal fetal fibrinogen testing ${ }^{4}$.

Prevention of PTB, in recent healthcare services, has been most important desiderate in obstetrics and a necessity of society, however achievement of these goals remains elusive so far. Since 1970s, progesterone is being used for the prevention of preterm deliveries, however earlier evidences generated were fraught by mixed findings as well as were also based upon results of the underpowered studies, having weak methodologies particularly for eligibility criteria. These evidences also included history of spontaneous abortion as a treatment indication ${ }^{5}$.

Recently, use of progesterone has again emerged as potential pharmacological treatment modality for the improvement of pregnancy outcomes among population subsets who are at increased risk of preterm labor. During pregnancy, use of endogenous steroid hormones has been well established for the regulation of endocrine pathways. Estrogens have the potential to help sustain pregnancy to its full terms as well as termination of pregnancy by initiation of labor. Estrogens can help maintain the pregnancy by promoting their ability to synthesize progesterone ${ }^{6}$. Progesterone is primarily responsible for maintaining pregnancy across the various 
phenomenon such as morphological changes of the cervix and myometrium, inhibits uterine contractions and also down regulation of immune system systematically as well as maternal fetal interface ${ }^{7-12}$. A study conducted by Ibrahim et $\mathrm{al}^{10}$ concluded that progesterone prevented preterm labor in $68 \%$ of the women with previous history of preterm labor. Mean gestational age was $37.47 \pm 1.55$ weeks in their study cases. Another study conducted by Ahmed et $\mathrm{al}^{11}$ reported prevention of preterm labor in $66 \%$ pregnant ladies with previous history of preterm deliveries.

This proposed study is done to document the frequency of prevention of preterm labor after treated with oral progesterone to draw evidence from our population regarding efficacy of oral progesterone to prevent preterm birth.

\section{Material and methods}

All women (345) with previous history of preterm delivery, aged less than 45 years of age having their gestational ages 15 - 20 weeks were included from January 2018 to May 2019 at Department of Gynecology and Obstetrics, Nishtar Hospital Multan. Patients with history of regular uterine contractions, scarred uterus and presence of fetal anomalies, diabetes, UTI and pre-eclampsia were excluded from our study. Once registered these study cases were arranged for all baseline investigations including ultrasonography. These study cases were given $400 \mathrm{mg}$ oral progesterone every day till delivery and were followed till delivery to record prevention of preterm birth (efficacy; birth of a baby with more than 37 weeks gestational age assessed on LMP treated with oral progesterone). Data were analyzed by using SPSS Version 20. Mean and standard deviation was calculated for the numerical data like age of patients, gravidity, parity and gestational age. Frequencies and percentages were tabulated for qualitative variables like age groups, preterm labor and type of pregnancy (singleton/multiple).

\section{Results;}

Our study comprised of a total of 345 pregnant women with previous history of preterm labor who met inclusion criteria of this study. Mean age of our study cases was $30.12 \pm 4.83$ years (range $22-41$ years) and $179(51.9 \%)$ had their age ranging from 20 - 30 years. Mean parity of our study cases was $4.52 \pm 1.19$ (with minimum parity was 3 while maximum was para 7) and majority of these women i.e. $228(66.1 \%)$ belonged to the group having parity $3-5$. Mean gravidity of our study cases was $5.66 \pm 1.18$ (with minimum gravidity was 4 while maximum with gravidity 8$)$ and most of the ladies i.e. $199(57.7 \%)$ had gravidity equal to or less than 5. Mean gestational age of our study cases was $37.51 \pm 1.34$ weeks at the time of delivery (with minimum gestational age was 32 weeks while maximum was 39 weeks). Mean body mass index of our study cases was $23.39 \pm 2.87 \mathrm{~kg} / \mathrm{m}^{2}$ (with minimum BMI was 20.5 while maximum was $31 \mathrm{~kg} / \mathrm{m}^{2}$ ). Mean height was $152.09 \pm$ 10.66 centimeters while mean weight of our study cases was noted to be $52.38 \pm 7.40$ kilograms. Our study results have indicated that obesity was present in $83(24.1 \%)$ study cases. Of these 345 study cases, 180 (52.2\%) belonged to urban areas, $328(95.1 \%)$ had singleton pregnancy and previous no. of preterm births ranging from 1 - 2 was noted in $240(69.57 \%)$. Treatment with oral progesterone prevented preterm labor in $231(67 \%)$ of the study cases.

\section{Discussion;}

Oral progesterone is being widely used among pregnant women due to its therapeutic application to prevent preterm births, recurrent miscarriages and treatment of threatened pregnancies ${ }^{13-15}$. Progesterone has got the capability to quiet the gravid uterus which ultimately allows pregnancy to physiologically attain full term in a natural way ${ }^{16}$. It bears ability to block impacts of oxytocin in terms of prostaglandin F2 [alpha] and [alpha]adrenergic stimulation and therefore increases the [alpha]-adrenergic tocolytic response when it is in sufficient levels in the myometrium ${ }^{17,18}$.

Our study comprised of a total of 345 pregnant women with previous history of preterm labor who met inclusion criteria of this study. Mean age of our study cases was $30.12 \pm 4.83$ years (with minimum age was 22 years while maximum age was 38 years). Our study results have indicated that majority of our study cases i.e. 179 (51.9\%) had their age ranging from 20 - 30 years. Similar results have been reported by Ibrahim et al 10. Ahmed et al ${ }^{11} 27.42 \pm 3.84$ years mean age which is similar to that of our study results. Meis et al ${ }^{19}$ reported mean age to be $26.0 \pm 5.6$ years which is close to our study results. Mean parity of our study cases was $4.52 \pm$ 1.19 (with minimum parity was 3 while maximum was para 7) and majority of these women i.e. 228 (66.1\%) belonged to the group having parity $3-5$. Our findings are in compliance with that of Meis et al ${ }^{19}$. Mean gravidity of our study cases was $5.66 \pm 1.18$ (with minimum gravidity was 4 while maximum with gravidity 8 ) and most of the ladies i.e. $199(57.7 \%)$ had gravidity equal to or less than 5. Ibrahim et al ${ }^{10}$ reported $3.96 \pm 1.04$ which is close to our study results. 
Mean gestational age of our study cases was $37.51 \pm 1.34$ weeks (with minimum gestational age was 32 weeks while maximum was 39 weeks). Ibrahim et al ${ }^{10}$ reported $37.47 \pm 1.55$ week which is similar to that of our study results. Meis et al ${ }^{19}$ reported similar results. Mean body mass index of our study cases was $23.39 \pm$ $2.87 \mathrm{~kg} / \mathrm{m}^{2}$ our study results have indicated that obesity was present in $83(24.1 \%)$ study cases. Of these 345 study cases, $180(52.2 \%)$ belonged to urban areas, $328(95.1 \%)$ had singleton pregnancy and previous no. of preterm births ranging from $1-2$ was noted in $240(69.57 \%)$. Meis et al ${ }^{19}$ reported $26.9 \pm 7.9 \mathrm{~kg} / \mathrm{m}^{2} \mathrm{BMI}$, considering BMI values in American population, these findings are close to our study results.

Progesterone is a necessary steroid hormone required in the endocrinological milieu of females that plays essential roles in various phases of human reproduction. Its roles include the proper regulation of menstrual cycle, embryo implantation and pregnancy maintenance until term. Treatment with oral progesterone prevented preterm labor in $231(67 \%)$ of the study cases. Rai et al ${ }^{20}$ reported $61 \%$ prevention of preterm birth with oral progesterone. These findings are close to our study results. A study conducted by Ibrahim et al ${ }^{10}$ concluded that progesterone prevented preterm labor in $68 \%$ of the women with previous history of preterm labor. Mean gestational age was $37.47 \pm 1.55$ weeks in their study cases. Another study conducted by Ahmed et al ${ }^{11}$ reported $^{2}$ prevention of preterm labor in $66 \%$ pregnant ladies with previous history of preterm deliveries. Meis et al 19 reported $64 \%$ prevention of preterm birth which is again close to our study results.

\section{Conclusion;}

Our study results support the use of oral progesterone as use of oral progesterone was successful in preventing preterm labor in our study. Its use was found to be safe and reliable, hence can be given to the women with previous history of preterm birth without any adverse side effect. The prevention of preterm birth was significantly associated with age, parity, gravidity, no. of previous preterm births, order of pregnancy and residential status.

\section{References;}

1. D C, Lu MC. The contribution of maternal stress to Preterm birth: issues and considerations. Clin Perinatol. 2011;38(3):351-84.

2. Kramer MS, Papageorghiou A, Culhane J, Bhutta Z, Goldenberg RI, Gravett M, et al. Challenges in defining and classifying the preterm birth syndrome. Am J Obstet Gynecol. 2012;206(2):108-12.

3. Hall NR. What agent should be used to prevent recurrent preterm birth: 17-P or natural progesterone? Obstet Gynecol Clin North Am. 2011;38(2):235-46.

4. Norwitz ER, Caughey AB. Progesterone supplementation and the prevention of preterm birth. Rev Obstet Gynecol. 2011;4(2):60-72.

5. Vidaef AC, Belfort MA. Critical appraisal of the efficacy, safety, and patient acceptability of hydroxyprogesterone caproate injection to reduce the risk of preterm birth. Patient Prefer Adherence. 2013;7:683-691.

6. Babischkin JS, Grimes RW, Pepe GJ, Albrecht ED. Estrogen stimulation of P450 cholesterol side-chain cleavage activity in cultures of human placental syncytiotrophoblasts. Biol Reprod. 1997;56(1):272-8.

7. Vidaeff AC, Ramin SM. Potential biochemical events associated with initiation of labor. Curr Med Chem. 2008;15(6):614-9.

8. Mendelson CR. Minireview: fetal-maternal hormonal signaling in pregnancy and labor. Mol Endocrinol. 2009;23(7):947-54.

9. Likis FE, Edwards DR, Andrews JC, Woodworth AL, Jerome RN, Fonnesbeck CJ, et al. Progestogens for preterm birth prevention: a systematic review and meta-analysis. Obstet Gynecol. 2012;120(4):897907.

10. Ibrahim M, Ramy ARM, Younis MA. Progesterone supplementation for prevention of preterm labor; a randomized controlled trial. Middle East Soc J. 2010;15:39-41.

11. Ahmed F, Yasir S, Naeem NK, Amin A. Efficacy of 17 alpha hydroxy progesterone in prevention of preterm labour in high risk patients. Ann King Edward Med Uni. 2012;18(2):158-62.

12. Jabeen S, Akhtar M, Fatima N, Akram M. Role of progesterone for the prevention of preterm labour. Pak J Med Health Sci. 2012;6(1):253-5.

13. Villar $\mathrm{J}^{1}$, Papageorghiou AT, Knight HE, Gravett MG, Iams J, Waller SA, et al. The preterm birth syndrome: a prototype phenotypic classification. Am J Obstet Gynecol 2012;206:119-23. 
14. Practice bulletin no. 130: prediction and prevention of preterm birth. Obstet Gynecol 2012;120:964-73.

15. Grobman $\mathrm{WA}^{1}$, Thom EA, Spong CY, Iams JD, Saade GR, Mercer BM, et al. 17 alphahydroxyprogesterone caproate to prevent prematurity in nulliparas with cervical length less than 30 mm. Am J Obstet Gynecol 2012;207:390.e1-8.

16. Rozenberg $\mathrm{P}^{1}$, Chauveaud A, Deruelle $\mathrm{P}$, Capelle $\mathrm{M}$, Winer $\mathrm{N}$, Desbrière $\mathrm{R}$, et al. Prevention of preterm delivery after successful tocolysis in preterm labor by 17 alpha-hydroxyprogesterone caproate: a randomized controlled trial. Am J Obstet Gynecol 2012;206:206.e1-9.

17. Sotiriadis A, Papatheodorou S, Makrydimas G. Perinatal outcome in women treated with progesterone for the prevention of preterm birth: a meta-analysis. Ultrasound Obstet Gynecol 2012;40:257-66.

18. Manuck TA ${ }^{1}$, Lai Y, Meis PJ, Dombrowski MP, Sibai B, Spong CY, et al. Progesterone receptor polymorphisms and clinical response to 17-alpha-hydroxyprogesterone caproate. Am J Obstet Gynecol 2011;205:135.e1-9.

19. Meis PJ, Klebanoff M, Thom E, Dombrowski MP, Sibai B, Moawad AH, et al. Prevention of recurrent preterm delivery by 17 alpha-hydroxyprogesterone caproate. N Engl J Med. 2003 Jun 12;348(24):237985.

20. Rai P, Rajaram S, Goel N, Ayalur Gopalakrishnan R, Agarwal R, Mehta S. Oral micronized progesterone for prevention of preterm birth. Int J Gynaecol Obstet. 2009 Jan;104(1):40-3. 